\title{
Sleep: The Evolution of Sleep Medicine in Neurology (Part One)
}

\author{
Krystle Minkoff* \\ ${ }^{1}$ Department of Neurosurgery, Landspitali University, Iceland \\ ${ }^{2}$ Department of oncology-pathology, Karolinska University Hospital, Sweden \\ ${ }^{3}$ Department of Plastic Surgery, Uppsala University Hospital, Sweden \\ ${ }^{4}$ Hospital Physics, Karolinska University Hospital, Sweden
}

Submission: November 02, 2016; Published: December 19, 2016

*Corresponding author: Krystle Minkoff, RPSGT, RST, American Academy of Sleep Medicine, 1136 Jerry Ln Bedford, Tx 76022 , USA, Tel: 817-455-9816; Email: the.krystle.minkoff@gmail.com

\section{Case Blog}

As we begin this journey to tackle the evolution of sleep medicine in neurology and examine the changes, it would behoove us to remind ourselves where it all started with the introduction of a man who is affectionately referred to as the "father" of sleep medicine. Born in 1928 in Wenatchee, Washington, William Dement is a pioneer of sleep medicine and founder of the Sleep Research Center at Stanford University. He is considered a leading authority on subjects such as sleep, sleep deprivation, and the diagnosis and treatment of sleep disorders such as sleep apnea and narcolepsy. He was eager to pursue sleeping subjects due to his interest in psychiatry and dreams. Studying some of the first recordings of electroencephalogram $(E E G)$, he was able to discover and name 5 stages of sleep.

Hence, we will dissect the various stages of sleep in the following pages summed up by purpose, rate, and differences in patterns as aging and life cycles occur. In mammals and birds, sleep is divided into two broad types: rapid eye movement (REM sleep) and non-rapid eye movement (NREM or nonREM sleep). Each type has a distinct set of physiological and neurological features associated with it. REM sleep is associated with dreaming, faster brain waves, loss of muscle tone, and suspension of homeostasis. REM and non-REM sleep are so contrasted that many physiologists classify them as distinctly separate behavioral states. To this degree, REM, non-REM, and waking represent the three major modes of consciousness, neural activity, and physiological regulation.

During non-REM sleep, the brain uses significantly less energy than during wakefulness. In areas with diminished activity, the brain restores its supply of adenosine triphosphate (ATP), which is the molecule used for short-term storage and transport of energy. During slow-wave sleep, humans secrete growth hormone. The secretion of prolactin is relevant to all sleep stages even while during the day.

The American Academy of Sleep Medicine (AASM) divides NREM into three stages: N1, N2, and N3, the last of which is also called delta sleep or slow-wave sleep. [1] The whole period normally proceeds in the order: N1 $\rightarrow \mathrm{N} 2 \rightarrow \mathrm{N} 3 \rightarrow \mathrm{N} 2 \rightarrow$ REM. In other animals the subdivision between phases of non-REM sleep is not typically used, although animal non-REM sleep can be described as lighter or deeper. NREM Stage 1 (N1- light sleep, somnolence, drowsy sleep-5-10\% of total sleep in adults): This is a stage of sleep that usually occurs between sleep and wakefulness, and sometimes occurs between periods of deeper sleep and periods of REM. The muscles are active, and the eyes roll slowly, opening and closing moderately. The brain transitions from alpha waves having a frequency of 8-13 Hz (common in the awake state) to theta waves having a frequency of 4-7 Hz. Sudden twitches and hypnic jerks, also known as positive myoclonus, may be associated with the onset of sleep during N1. NREM Stage 2 (N2- 45-55\% of total sleep in adults): [2] In this stage, theta activity is observed and sleepers become gradually harder to awaken; the alpha waves of the previous stage are interrupted by abrupt activity called sleep spindles (or thalamocortical spindles) and K-complexes. Sleep spindles range from 11 to $16 \mathrm{~Hz}$ (most commonly 12-14 Hz).

NREM Stage 3 (N3- deep sleep, slow-wave sleep-15-25\% of total sleep in adults): Formerly divided into stages 3 and 4 , this stage is called slow-wave sleep (SWS) or deep sleep. SWS is initiated in the preoptic area and consists of delta activity, high amplitude waves at less than $3.5 \mathrm{~Hz}$. The sleeper is less responsive to the environment; many environmental stimuli no longer produce any reactions. Slow-wave sleep is thought to be the most restful form of sleep. [3] 


\section{Open Access Journal of Neurology \& Neurosurgery}

This stage is characterized by the presence of a minimum of $20 \%$ delta waves ranging from $0.5-2 \mathrm{~Hz}$ and having a peakto-peak amplitude $>75 \mu \mathrm{V}$. (EEG standards define delta waves to be from 0 to $4 \mathrm{~Hz}$, but sleep standards in both the original R\&K, as well as the new 2007 AASM guidelines have a range of 0.5-2 Hz.) This is the stage where parasomnias such as night terrors, nocturnal Human sleep oscillates in 90 minute intervals, which include increasing nuresis, sleepwalking, and somniloquy occur. Many illustrations and descriptions still show a stage N3 with $20-50 \%$ delta waves and a stage $\mathrm{N} 4$ with greater than $50 \%$ delta waves; these have been combined as stage N3 [2]. REM Stage (REM Sleep-20-25\% of total sleep in adults) Known as rapid eye movement (REM) sleep where most muscles are paralyzed, and heart rate, breathing and body temperature become unregulated, the sleeper may dream.

REM sleep is initiated through acetylcholine secretion and inhibited by neurons that secrete monoamines including serotonin. During this stage, vital signs indicate arousal and oxygen consumption by the brain is higher than during wake. An adult reaches REM approximately every 90 minutes. The exact function of REM sleep is still a bit of a mystery; however, it appears that a lack of it impairs the ability to learn complex tasks. Paralysis from muscular atonia in REM may be necessary to protect organisms from damaging themselves through physical activity.

Now that we've dissected the various stages of sleep, we will study purposes, distributions, and patterns. Generally speaking, the longer an organism is awake, the more it feels the need to sleep. The balance between sleeping and waking is called homeostasis. This leads us to Circadian Rhythm. Proportions of paradoxical (REM) sleep as they repeat. This rhythm is called the ultradian sleep cycle. Early in 2015, after a two-year study, [4] the National Sleep Foundation in the US announced newly revised recommendations as shown in the (Table 1) below.

Table 1 :

\begin{tabular}{|c|c|}
\hline Age and Condition & Sleep Needs \\
\hline Newborns (0-3 months) & 14 to 17 hours \\
\hline Infants (4-11 months) & 12 to 15 hours \\
\hline Toddlers (1-2 years) & 11 to 14 hours \\
\hline Preschoolers (3-4 years) & 10 to 13 hours \\
\hline School-age children (5-12 years) & 9 to 11 hours \\
\hline Teenagers (13-17 years) & 8 to 10 hours \\
\hline Adults (18-64 years) & 7 to 9 hours \\
\hline Older Adults (65 years and over) & 7 to 8 hours \\
\hline
\end{tabular}

\section{References}

1. Silber MH, Ancoli-Israel S, Bonnet MH, Chokroverty S, Grigg-Damberger MM, et al. (2007) The visual scoring of sleep in adults. J Clin Sleep Med 3(2): 121-131.

2. Fuller Patrick M, Gooley Joshua J, Saper Clifford B (2006) Neurobiology of the Sleep-Wake Cycle: Sleep Architecture, Circadian Regulation, and Regulatory Feedback. J Biol Rhythms 21(6): 482-493.

3. Waterhouse Jim, Fukuda Yumi, Morita Takeshi (2012) Daily rhythms of the sleep-wake cycle. J Physiol Anthropol 31: 5.

4. Max Hirshkowitz, Kaitlyn Whiton, Steven M. Albert, Cathy Alessi, Oliviero Bruni, et al. (2015) National Sleep Foundation's sleep time duration recommendations: methodology and results summary. Sleep Health: Journal of the National Sleep Foundation. Elsevier Inc 1(1): 4043.

Your next submission with JuniperPublishers
will reach you the below assets
- Quality Editorial service
- Swift Peer Review
- Reprints availability
- E-prints Service
- Manuscript Podcast for convenient understanding
- Global attainment for your research
- Manuscript accessibility in different formats
( Pdf, E-pub, Full Text, audio)
- Unceasing customer service
Track the below URL for one-step submission
http://juniperpublishers.com/online-submission.php

